\title{
ADOPTION OF IMPROVED CULTIVARS OF PEARL MILLET IN AN ARID ENVIRONMENT: STRAW YIELD AND QUALITY CONSIDERATIONS IN WESTERN RAJASTHAN
}

\author{
By.T. G. KELLEY†, P. PARTHASARATHY RAO $\dagger$, \\ E. WELTZIEN R. $†$ and M. L. PUROHIT + \\ $\dagger$ International Crops Research Institute for the Semi-Arid Tropics (ICRISAT) \\ Patancheru, Andhra Pradesh, India and \\ $\ddagger$ Central Arid Zone Research Institute (CAZRI), Jodhpur, Rajasthan, India
}

(Accepted 30 July 1995)

\begin{abstract}
SUMMARY
The role of straw yield and quality in farmers' decisions about the adoption of pearl millet cultivars in western Rajasthan was examined using farm household surveys. Information on the relative importance of grain versus straw yield, the perceived risks associated with the use of new cultivars under variable climatic conditions and perceptions of straw quality indicated that improved cultivars of pearl millet were not adopted primarily because of poor grain yield in years with low rainfall, though poor straw yield in such years was also important. These results are particularly pertinent in the light of farmers' perceptions of the likelihood of experiencing drought or low rainfall. If new cultivars of pearl millet are to replace the traditional ones, they must perform better under conditions of limited rainfall.
\end{abstract}

\section{INTRODUCTION}

The integration of crop and livestock production is a characteristic feature of farming systems in the semi-arid tropics. Although crop production activities are important components of these systems, animal production activities often provide the main source of employment and income (Nordblom, 1983). Nevertheless, farmers in the semi-arid tropics cannot afford to allocate much, if any, of their limited cropland to forage crops, and few have access to sufficiently large communal grazing lands. Indeed, the area and quality of grazing lands have declined during recent times (Bhaskara Rao, 1994; Jodha, 1985), so that farm households typically rely on dual-purpose cereal and legume crops to provide both grain for their own consumption and stover for their livestock. This trend is likely to continue for some time to come (Kelley et al. 1993).

Pearl millet (Pennisetum glaucum [L.] R.Br.) is one such dual-purpose cereal crop and is grown extensively throughout the semi-arid regions of India. It is well adapted to heat, drought and poor soil fertility (Rachie and Majumdar, 1980). Modern cultivars, both hybrids and open pollinated varieties, developed by the 
Indian national programme in collaboration with the International Crops Research Institute for the Semi-Arid Tropics (ICRISAT), have been extensively adopted. Conservative estimates put the area of pearl millet sown to ICRISATderived cultivars at around 3.5 million hectares in India, equivalent to about one third of the total area of pearl millet grown (ICRISAT, 1993). In Gujarat, Tamil Nadu and Andhra Pradesh, almost $90 \%$ of the pearl millet area is planted to improved cultivars, and this has led to significant gains in productivity (Jansen, 1988).

Adoption rates are lower in the states of Haryana, Karnataka, and Maharashtra, particularly in their drier zones, and have barely reached $30 \%$ in Rajasthan, where about $40 \%$ of the country's pearl millet area is sown (Fertilizer Association of India, 1992). In the western and most arid part of the state, adoption of improved cultivars is even lower and traditional landraces with lower grain yield potential are most commonly grown. It is precisely in these areas, where dependence on the pearl millet crop is so great, that crop improvement is most needed but few studies to-date have looked into the factors associated with the limited adoption of new cultivars in these regions.

Breeding for improved productivity in marginal environments is generally hampered by large genotype $\times$ environment interactions, high chances of crop failure and the poor adaptation of much of the available breeding material to the extremes of stress factors prevalent in such environments (Weltzien, 1986; Geccarelli, 1994). Thus, genetic advances achieved under favourable conditions are not necessarily of benefit to farmers in marginal areas and breeding strategies which rely on an understanding of the prevalence of particular environmental stresses and on concepts for increased utilization of well adapted germplasm are more likely to succeed (Ludlow and Muchow, 1988; Ceccarelli et al., 1992; Bidinger et al., 1994).

The Indian national programme and that of ICRISAT have traditionally focused on improving disease resistance and grain yield potential by selection under good management conditions. Hardly any emphasis has been given to straw yield or quality, nor to grain yield, under the poor growing conditions typical of the major production areas in northwestern India. A detailed evaluation of the local germplasm from these areas showed that grain yields of the local cultivars under marginal conditions were higher than those of modern cultivars (Weltzien and Witcombe, 1989; Bidinger et al., 1994). This indicates that breeding efforts for pearl millet need to be better targeted to take into account the major production environments.

Performance involves more than just grain yield and must be viewed in the context of the total value of production, which involves grain yield and quality and straw yield and quality. Straw yield and quality may be particularly important in western Rajasthan where animal husbandry is a major source of income. There is evidence that straw quality plays a role in farmers'.adoption decisions. Kshirsagar et al. (1987), for example, found that higher straw yield and better straw quality were among several reasons given by farmers for preferring 
an improved pearl millet variety to a hybrid in Maharashtra, and there is similar evidence for other dual-purpose cereal crops both within and outside India (Kelley and Parthasarathy Rao, 1994; Reed et al., 1988, Nygaard, 1983).

Clearly, more direct evidence is needed to explain the limited adoption of improved pearl millet cultivars in arid environments. A critical component in this process is eliciting information from farmers about their production objectives: the relative importance of grain versus straw yield, the perceived risks associated with the use of new cultivars under variable climatic conditions, preferred straw quality characteristics, and preference for a single or dual purpose plant type. In addition, the hypothesis that straw yield and quality considerations play a key role in farmers' adoption decisions needs to be examined more critically.

This paper addresses these issues, drawing on results of farm household surveys carried out in selected locations in the semi-arid regions of India to test whether straw yield and quality considerations influence farmers' decisions to adopt or reject modern cultivars of pearl millet.

\section{METHODOLOGY}

Jodhpur District was selected for the surveys because of its central location in western Rajasthan and because the Central Arid Zone Research Institute (CAZRI) is located there. It is one of 11 desert districts in western Rajasthan. Three criteria were considered in selecting the four villages for the household survey: average rainy season rainfall, road accessibility, and distance from Jodhpur. The district was divided into two zones on the basis of rainfall, and hence production potential: high (above $400 \mathrm{~mm}$ annual rainfall) and low (below $400 \mathrm{~mm}$ ). Two villages were selected from each zone that were reasonably accessible from the road. One village was selected because of its close proximity to Jodhpur town, largely to allow for the possible effect on adoption decisions of fodder marketing considerations. Once the villages had been chosen and individual farm households identified, a random sample of 20 households, stratified by farm size, was taken for each of the four villages. The household surveys were conducted during the 1990-91 cropping season.

Individual farmer questionnaires (pre-tested and subsequently modified) were administered by field research assistants under the supervision of ICRISAT and CAZRI senior staff. Farmer responses were recorded onto the questionnaire forms and later coded, entered, and cleaned before analysis. The survey was designed to examine farmers' perceptions and preferences on the following issues:

- The incidence of good, normal, and low rainfall and drought conditions within their village and their importance in relation to expected crop yields, that is, the rainfall conditions associated with good, average, low and zero (or negligible) crop yields.

- The importance of straw yield as a production objective relative to grain yield under both good and poor rainfall conditions. 
- Varietal performance with respect to straw yield and quality in improved and traditional varieties.

- In the two villages where traditional varieties of pearl millet were extensively grown, farmers were asked to rank four key reasons for not growing improved cultivars. A previous survey had identified four major disadvantages associated with improved cultivars: low grain yield in poor rainfall years, low fodder yields in poor rainfall years, poorer grain quality and poorer fodder quality.

- Farmers were asked to rank five straw quality characteristics: leafiness, stem thickness, colour, height and sweetness in order of preference.

- General questions were asked in relation to such matters as fodder availability, fodder purchases/sales (by type), and number and type of animals kept, especially with respect to changes over time.

- Perceptions of problems relating to seed quality or availability and farmers' seed management strategies (that is, re-use of seed) were elicited through both individual and group interviews (see below).

Because of the qualitative nature of the data - much of it is measured on an ordinal or categorical scale - the analysis relied on simple tabulations and comparisons of frequencies of responses. Whenever possible, statistical tests of significance were carried out using non-parametric tests such as the Chi-square test (to examine consistency in preference patterns across the four villages) and Friedman's two-way analysis of variance for analysing ranked data (Siegel and Castellan, 1988).

To complement the individual surveys, informal (pre-survey) discussions were held with groups of farmers in each village to elicit more descriptive information covering a range of topics from seed quality and availability to village characterization. This information, supplemented by secondary data such as those on rainfall, soil type, and irrigation extracted from the Jodhpur District Census Handbook (Government of Rajasthan, 1986) was used in characterizing key aspects of the farming systems in these villages.

\section{RESULTS}

During the two-year period 1990-1991, annual rainfall ranged between 290 and $400 \mathrm{~mm}$ across the four villages (unpublished data from local taluka offices). Pearl millet was the main cereal crop grown and was used as a food grain, with the stover being used as livestock feed. Pearl millet is mostly grown as a mixed crop with greengram (Vigna radiata), moth (Vigna aconitifolia), cluster bean (Cyamopsis tetragonoloba) and a range of cucurbits. These crops are important in the drier, more remote northwestern region of Jodhpur district where two of the four villages sampled in this study, Baleswar and Ramalwara, are located. The other two villages, Pichayak and Doli, are further east and have better access to Jodhpur city. Here, rainfall is slightly higher, and other crops such as sorghum (Sorghum bicolor), wheat (Triticum aestivum), and sesame (Sesamum indicum L.) 
become important. Better infrastructure and greater use of inputs is evident. Characteristic features of the four villages are presented in Table 1.

In the driest part of Jodhpur District the soils are sandy and have a limited water holding capacity (Kalla and Goyal, 1987). During the 1990 rainy season $15 \%$ (Baleswar) and 30\% (Ramalwara) of the cultivable area were left fallow. Most of the farmers grew traditional (desi) pearl millet cultivars. Pure $\left(\mathrm{F}_{1}\right)$ hybrids were seldom used, although use of advanced generation hybrids was not uncommon. Raising goats, sheep, and cows was an important economic activity and represented a major source of income for these households. By contrast, in Doli and Pichayak most farmers used $F_{1}$ hybrids and improved open-pollinated varieties of pearl millet, mainly under sole cropped conditions. Advanced generation hybrids were also used to a limited extent. In this relatively better endowed region, cows and buffaloes tend to be more important than goats and sheep.

\section{Farmers' perceptions}

Across all four villages, the general expectation was that poor performance resulting from drought or low rainfall was likely to occur in more than half the years. There was a clear and consistent perception about the riskiness and low productivity potential of these environments. Farmers in the higher rainfall villages had much the same perception about the frequency of rainfall as farmers in the drier areas, indicating that farmers' expectations were relative to what was normal in their area.

The relative importance of straw yield varied according to the type of year (Table 2). In a good or normal rainfall situation, only $5 \%$ of the respondents considered straw yield to be more important than grain yield; another $13 \%$ considered grain yield to be more important. For the vast majority, grain and straw yield were of equal importance, with no significant differences in preference patterns across the four villages. Thus, even under better growing conditions, when fodder from other sources was likely to be available, straw yield considerations were as important as grain yield.

For years with poor rainfall, a different picture emerged. Over half the farmers interviewed considered straw yield to be more important than grain yield. In the better endowed villages of Pichyak and Doli, almost $75 \%$ of the farmers regarded straw yield to be more important than grain yield during years of low rainfall. While the relative importance of straw yield during low rainfall years also increased in the drier villages, only about $40 \%$ there indicated that straw yield was more important than grain yield. Indeed, the same number of farmers considered straw and grain yield to be of equal importance. Another 20\% considered grain yield to be more important. This result may reflect the greater dependence on pearl millet as a source of human food grain, as well as the often semi-nomadic form of animal husbandry practised in the drier parts of Rajasthan.

Farmers' perceptions about the straw yield performance of traditional and improved cultivars also varied depending on' the type of year. Across the four 


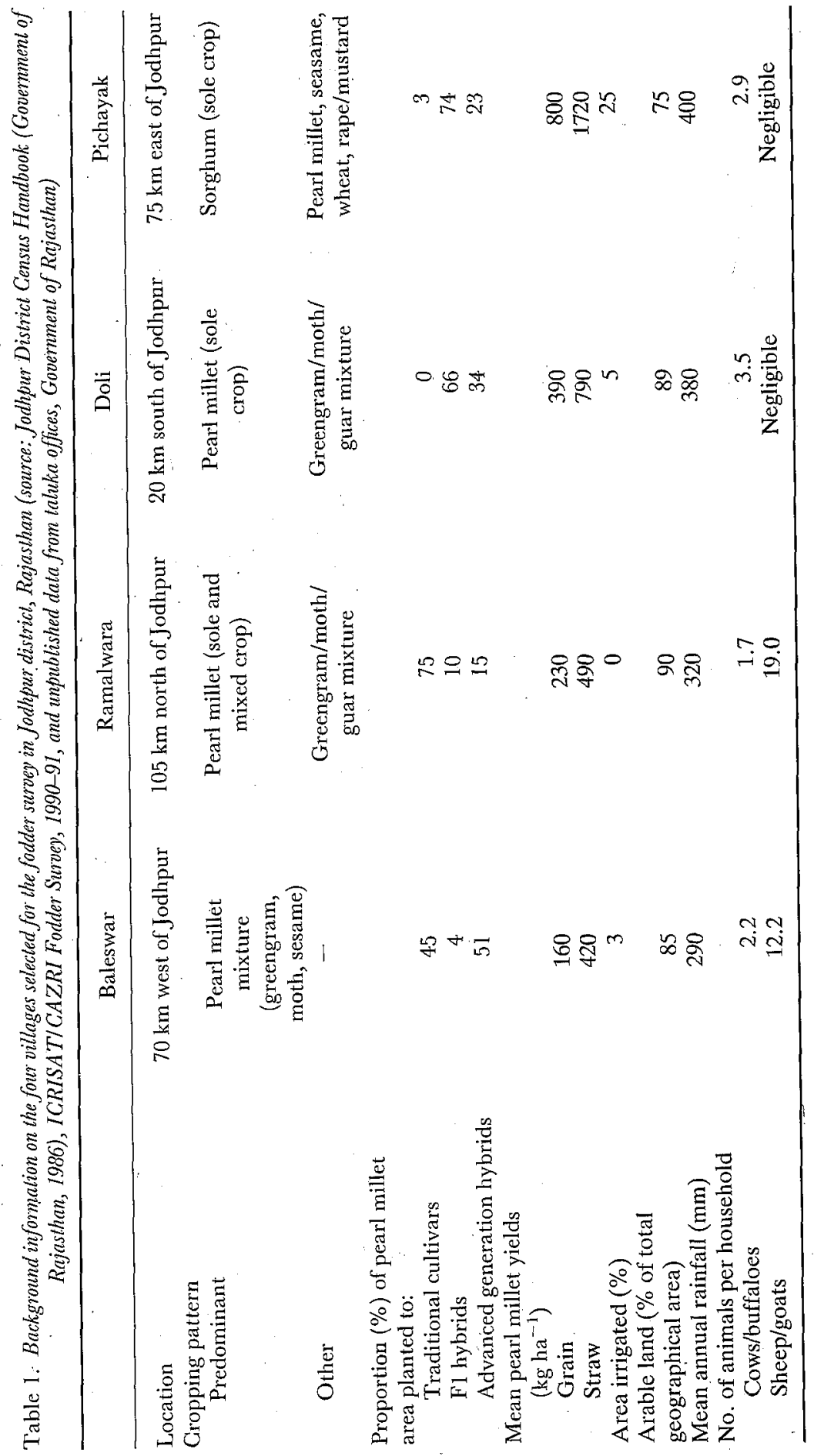


villages only $17 \%$ of the respondents considered that the traditional varieties of pearl millet produced a higher straw yield under good rainfall conditions (Table 3). Even in Ramalwara, the driest of the villages, and the village where improved cultivars have found least acceptance, the percentage was less than $30 \%$.

More than $80 \%$ of the respondents in each of the four villages surveyed considered that traditional cultivars yielded more straw than improved cultivars under low rainfall conditions and virtually all of the farmers in the drier villages expressed this view. Since pearl millet straw plays such a fundamental role in these livestock-based systems, this perception is likely to influence farmers' decisions about adopting new cultivars. In addition, approximately $90 \%$ of the farmers interviewed across the four villages considered that traditional cultivars of pearl millet had better straw quality.

Results also indicated that in the two drier villages where traditional cultivars predominate, improved cultivars were not adopted primarily because of poor grain yield performance in low rainfall years (Table 4). Virtually all the farmers interviewed in these villages listed low grain yield in low rainfall years as the primary reason for non-adoption; another one-third also included low straw yield. Poor grain and straw quality associated with hybrids and improved varieties were

Table 2. Farmers' perceptions (\%) of the relatioe importance of pearl millet straw yields in a normal rainfall and low rainfall year in four villages in Jodhpur District, Rajasthan

\begin{tabular}{|c|c|c|c|c|c|c|c|}
\hline \multirow[b]{2}{*}{ Village } & \multicolumn{3}{|c|}{ Good rainfall } & \multicolumn{3}{|c|}{ Low rainfall } & \multirow[b]{2}{*}{$\begin{array}{c}\text { Sample } \\
\text { size }\end{array}$} \\
\hline & $\begin{array}{c}\text { Grain } \\
> \\
\text { straw }\end{array}$ & $\begin{array}{l}\text { Grain } \\
= \\
\text { straw. }\end{array}$ & $\begin{array}{c}\text { Grain } \\
< \\
\text { straw }\end{array}$ & $\begin{array}{c}\text { Grain } \\
> \\
\text { straw }\end{array}$ & $\begin{array}{l}\text { Grain } \\
= \\
\text { straw }\end{array}$ & $\underset{\text { straw }}{\stackrel{\text { Grain }}{<}}$ & \\
\hline Baleswar & 10 & 90 & 0 & 20 & 40 & 40 & 20 \\
\hline Ramalwara. & 10 & 86 & 4 & 24 & 38 & 38 & 21 \\
\hline Doli & 6 & 84 & 10 & 11 & 26 & 63 & 19 \\
\hline Pichayak & 25 & 70 & 5 & 5 & 10 & 85 & 20 \\
\hline Mean & 13 & 83 & 5 & 15 & 29 & 56 & 20 \\
\hline
\end{tabular}

$\dagger>$ more important; $=$ of equal importance; < less important.

Table 3. Farmers' perceptions of the relative importance of the strawe yield of traditional and improved pearl millet cultivars in a normal and low rainfall year in four villages in Jodhpur District, Rajasthan

Farmers indicating higher straw yield obtained from traditional cultivars (\%)

\begin{tabular}{lccc} 
& Good rainfall year & Low rainfall year & Sample size \\
\hline Baleswar & 16 & 100 & 19 \\
Ramalwara & 28 & 100 & 20 \\
Doli & 0 & 82 & 17 \\
Pichayak & 20 & 80 & 20 \\
Mean & 17 & 91 & 19 \\
\hline
\end{tabular}


other reasons cited but ranked as less important. Seed availability was not a constraint to adoption in these four villages as they all have relatively good access to major agricultural markets, but this may be more important in more remote areas of Rajasthan.

\section{Straw and seed quality characteristics}

Thin stems were considered the most desirable quality trait of pearl millet straw in all four villages but in two of them, Ramalwara and Pichayak, leafiness and thin stem were equally preferred. Light straw colour was also given some consideration by farmers in Pichayak, whereas height and sweetness were not regarded as important characteristics. It is not clear whether thin stems are valued in their own right or because they are associated with the more palatable traditional varieties; thick stems are associated with the less palatable hybrid straw.

Those farmers who grew hybrids in Baleswar and Ramalwara often used more advanced generation hybrids rather than new $\mathrm{F}_{1}$ seed. In Baleswar village, only $4 \%$ of the pearl millet area was sown with $\mathrm{F}_{1}$ hybrids, but $51 \%$ was sown with advanced generation seed of these hybrids (Table 1). Even in Doli and Pichayak, the relatively better endowed villages, 25 to $30 \%$ of the area was sown with advanced generation pearl millet hybrids and the rest with $\mathrm{F}_{1}$ seed.

Farmers were aware of the yield loss associated with the use of second and third generation hybrid seed but believed yields stabilize after two or three years. More importantly, there was a belief that the risk of grain and straw yield loss during low rainfall years was less when second or third generation seed, rather than $\mathrm{F}_{1}$ seed, was used. Second and third generation hybrid seed was also more acceptable in terms of grain and straw quality [see Almekinders et al. (1994) on the importance of local seed systems in ensuring a diverse and flexible seed supply].

Though there appeared to be more than one type of hybrid in use, few farmers could identify the specific name of the hybrid they used and they were not usually aware of the differences between $F_{1}$ hybrids and open-pollinated varieties (both

Table 4. Reasons given by farmers for not growing improved pearl milet cultivars, ranked by order of importance ( $I=$ most important, $4=$ least important $)$ in two villages in Jodhpur District, Rajasthan

\begin{tabular}{|c|c|c|c|c|c|}
\hline \multirow{2}{*}{$\begin{array}{l}\text { Reasons for not } \\
\text { growing hybrids }\end{array}$} & \multicolumn{4}{|c|}{ No. of respondents giving a rank of } & \multirow{2}{*}{$\begin{array}{l}\text { Overall } \\
\text { rank }\end{array}$} \\
\hline & 1 & 2 & 3 & 4 & \\
\hline $\begin{array}{l}\text { Low grain yield in } \\
\text { low rainfall years }\end{array}$ & 33 & 0 & 1 & 0 & 1 \\
\hline $\begin{array}{l}\text { Low straw yield in } \\
\text { low rainfall years }\end{array}$ & 11 & 18 & 3 & 2 & 2 \\
\hline Poor grain quality & 1 . & 11 & 15 & 7 & 3 \\
\hline Poor straw quality & 0 & 15 & 12 & 7 & 3 \\
\hline
\end{tabular}


are called shankar), although both were distributed through the same public and private channels. Modern varieties were readily available in all the villages, so seed availability did not appear to be a constraint to adoption though a few farmers expressed concern about the poor quality of the hybrid seed being sold. This concern may be justified as advanced generation material of $F_{1}$ hybrids is sometimes sold as seed of improved open-pollinated varieties (C. T. Hash, personal communication, 1994).

\section{DISGUSSION AND CONGLUSIONS}

Our results indicate that improved cultivars of pearl millet are not adopted primarily because of poor grain yield in low rainfall years. Recent data from Weltzien et al. (1994) in a similar study area support this conclusion and indicate a strong farmer preference for earliness. Poor straw yield under low rainfall conditions ranked second in our list of factors responsible for non-adoption. These results are particularly pertinent in the light of farmers' perceptions about the likelihood of drought or low rainfall conditions. In all four villages sampled, farmers expect drought or low rainfall to occur in more than half the years and it is during such years that the relative importance of straw yield increases, as found also by Kelley and Parthasarathy Rao (1994). Dependence on crop residues increases in low rainfall years since alternative sources of fodder (such as green grass, cultivated forage crops and fodder from grazing land) are not readily available so that straw prices tend to rise sharply relative to grain prices. During particularly sévere droughts, adequate supplies of straw are simply not available. The problem is not as serious for grain because grain markets in India are regulated and better developed (Kelley et al., 1993).

One interesting and unexpected result was that farmers in the better endowed villages placed greater importance on straw yield during low rainfall years than those in the drier villages (Table 3). This may be because there are usually larger numbers of dairy animals in the better endowed villages so that the impact of reduced supplies of pearl millet straw would be worse than in the drier villages where milk animals are relatively less important. Goats and sheep tend to predominate in the drier villages and these animals generally depend less on straw. The results also indicate that there is a wider spread of opinions and preferences in the drier villages when low rainfall conditions prevail (Table 3), possibly because of differences in the relative importance of animal husbandry among individual farm families within the drier villages and in the degree of dependence on pearl millet as a staple food. This emphasizes the need to understand differences in the endowments of individual families and their effect on food security and self-sufficiency goals. This issue has important implications for crop improvement research, particularly in view of ICRISAT's mandate to target poor farm households.

This study has three important implications for crop improvement in pearl millet. The first is the need to bear in mind that riskiness of production is a major 
consideration for farmers when making decisions about the adoption of new varieties in this arid environment. Farmers give more weight to yield performance under low rainfall conditions, which explains the continued use of traditional cultivars in the two drier villages. In the other two villages many farmers are using second or third generation hybrid seed, since this is perceived to reduce the risk of yield loss during low rainfall years, compared with $\mathrm{F}_{1}$ seed. Risks are associated with both grain and straw yields. If new cultivars of pearl millet are expected to replace the traditional ones, it is essential that they are selected for better performance during low rainfall or even drought conditions. The selection of new hybrids or open-pollinated varieties at present is carried out under well-managed growing conditions on research stations with no consideration of results in drought-stressed conditions. Indeed, results from trials with mean yields below the Rajasthan state long-term average for grain yield have been rejected so that trials relevant to poor rainfall years have not been included in the data from which national (and state) cultivar release decisions are made. This is a major flaw in the trials system for dryland pearl millet (C. T. Hash, personal communication, 1994).

The second implication is that straw yield needs to be considered as a major selection criterion for breeding programmes targeting areas in western Rajasthan. At present, straw yield is rarely measured in routine selection programmes of pearl millet. Furthermore straw yield data are rarely considered in the release process for new cultivars, or if so, only as a secondary trait.

Thirdly, farmers are aware of quality differences and associate better quality traits with traditional cultivars. Visible quality traits could easily be used by breeders to develop genotypes with enhanced acceptability and adoptability in western Rajasthan. Hybrids and improved varieties have thicker stems and are usually fed to animals only after chopping. Chopped straw is often mixed with green fodder or with salt water to make it more palatable to the animals. There is also considerable wastage of straw associated with improved cultivars.

Acknowledgements. The authors would like to thank Mr Parihar and Mr Pareek of CAZRI for their help in conducting the surveys and $\mathrm{Mr} \mathrm{E}$. Jagadeesh for his assistance in data processing and table preparation. Comments from $\mathrm{C}$. T. Hash and two journal referees on earlier drafts of this paper are gratefully acknowledged. Financial support for field surveys in this study was provided by the Rockefeller Foundation.

\section{REFERENCES}

Almekinders, C. J. M., Louwaars, N. P. \& de Bruijn, G. H. (1994). Local seed systems and their importance for an improved seed supply in developing countries. Euphytica 78:207-216.

Bhaskara Rao, G. (1994) Grazing pressure and degradation of common grazing land in Andhra Pradesh, India: Examinations of supply side ramification. New Delhi: Resource Economics Unit, Society for Promotion of Wastelands Development. 
Bidinger, F. R., Weltzien R., E., Mahalaskshmi, V. S. \& Rao, K. P. (1994). Evaluation of landrace topcross hybrids of pearl millet for arid zone environments. Euphytica 76:215-226.

Ceccarelli, S., Valkoun, J., Erskine, W., Weigand, S., Miller, R. \& van Leur, J. A. G. (1992). Plant genetic resources and plant improvement as tools to develop sustainable agriculture. Experimental Agriculture 28:89-98.

Ceccarelli, S. (1994). Specific adaptation and breeding for marginal areas. Euphytica 77:205-219.

Fertilizer Association of India (1992). Fertilizer Statistics, 1991/92. New Delhi: Fertilizer Association of India.

Government of Rajasthan (1986). Jodphur District Census Handbook (Census of India 1981). Jaipur, Rajasthan: Office of Census Operations.

ICRISAT (1993). ICRISAT Report 1992. Patancheru, India: International Grops Research Institute for the Semi-Arid Tropics.

Jansen, H. G. P. (1988). Adoption of Modern Cereal Cultivars in India: Determinates and Implications of Inter-regional Variation in the Spread and Ceiling of Diffusion. PhD Thesis, Cornell University, Ithaca, New York.

Jodha, N. S. (1985). Population growth and the decline of common property resources in Rajasthan, India. Population and Development Review II, No. 2. 247-64.

Kalla, J. C. \& Goyal, D. (1987). Annual Report 1986: Impact of Livestock Productizity on Rural Economy in Arid Areas of Western Rajasthan. CAZRI, Jodhpur: Division of Agricultural Economics and Statistics.

Kelley, T. G., Parthasarathy Rao, P., \& Walker, T. S. (1993). The relative value of cereal straw fodder in the semi-arid tropics of India: Implications for the cereal breeding program at ICRISAT. In Research for Agricultural Technology Development: Spatial and Temporal Dimensions. 88-105 (Ed. Karen Ann Dvorak). Wallingford, Oxfordshire: CAB International.

Kelley, T. G. \& Parthasarathy Rao, P. (1994). Yield and quality characteristics of improved and traditional sorghum cultivars: Farmers' perceptions and preferences. In Variation in the Quantity and Quality of Fibrous Crop Residues: Proceedings of a National Seminar held at the BAIF Development Research Foundation, Pune, Maharashtra, 8-9 February 1994, 133-145 (Eds A. L. Joshi, P. T. Doyle and S. J. Oosting). Pune, India: BAIF Development Research Foundation.

Kshirsagar, K. G., Bhende, M. J., Pawar, M. N., Chopde, V. K., \& Walker, T. S. (1987). Acceptance of an improved variety competing with hybrids: Farmers' perceptions and early adoption of WC-C.75 pearl millet variety in western Maharashtra. Patancheru, India: Economics Program Report, International Crops Research Institute for the Semi-Arid Tropics.

Ludlow, M. M. \& Muchow, R. C. (1988) Critical evaluation of the possibilities for modifying crops for high production per unit precipitation. In Drought Research Priorities for the Dryland Tropics, 179-211 (Eds F. R. Bidinger and C. Johansen). ICRISAT: Patancheru, India.

Nordblom, T. L. (1983). Livestock-crop interactions. The decision to harvest or to graze a mature grain crop. Discussion Paper No. 10, Aleppo, Syria: ICARDA.

Nygaard, D. (1983). Tests on farmer's fields: The ICARDA experience. In Proceedings of the First Farming Systems Research Symposium, 76-98. Manhattan, Kansas, USA: Kansas State University.

Rachie, K. O. \& Majumdar, J. V. (1980). Pearl Millet. Pennsylvania, USA: State University.

Reed, J. D., Capper, B. S. \& Neate, P. J. (1988). Plant Breeding and the Nutritive Value of Crop Residues. Proccedings of a Workshop held at ILCA, Addis Ababa, Ethiopia, 7-10 December 1987, 255. Addis Ababa, Ethiopia: ILCA.

Siegel, S. \& Gastellan, N. J. (1988). Nonparametric Statistics for the Behavioral Sciences. New York: McGrawHill.

Weltzien, E. 1986. Anpassungsfähigkeit nahöstlicher Landgersten an marginale Wachstumsbedingungen. Dissertation, TU München, Freising-Weihenstephan.

Weltzien, E. \& Witcombe, J. R. (1989) Pearl millet improvement for the Thar Desert, Rajasthan, India. Vortrage fur Pfanzenzuchtung 15:23-26.

Weltzien R., E., Whitaker, M. L., Kshirsagar, K. G., Anders, M. M. \& Voortman, U. (1984). Traits used by farmers in Rajasthan to differentiate pearl millet cultivars. In Cereal Program Annual Report 1993, 8791. Patancheru, India: ICRISAT. 